\title{
Segmental dilatation of ileum in a child with juvenile idiopathic arthritis, localized myopathy with focal stasis induced immunogenic injury as a possible etiology: a case report
}

\author{
Santosh Kumar Mahalik ${ }^{1 *}$ (D), Susama Patra ${ }^{2}$, Bikasha Bihary Tripathy ${ }^{1}$, Akash Bihari Pati ${ }^{1}$,
} Manoj Kumar Mohanty ${ }^{1}$ and Subash Chandra Samal ${ }^{3}$

\begin{abstract}
Background: Segmental dilatation of the intestine (SDI) though uncommon is a well-known entity and more than 150 cases of SDI are reported in the literature. The presentation and association of SDI are well described; however, the association of SDI with juvenile idiopathic arthritis (JIA) has not been reported earlier. We described a case of SDI with JIA, who presented with malnutrition and chronic abdominal distension.

Case presentation: A 5-year-old female child was getting treated for JIA and referred to us for evaluation of chronic abdominal distension. On laparotomy, a huge SDI was found approximately $40 \mathrm{~cm}$ from the ileocecal junction and resection of the dilated part with approximately $2-3 \mathrm{~cm}$ of healthy ileum on each side and anastomosis was performed. The child recovered well and the features of arthritis also resolute 6 weeks later. From histologic analysis, we have suggested role of localized myopathy in development of segmental dilatation. We have further emphasized the link between the SDI with development of arthritis.

Conclusion: Etiology of SDI is multifactorial with architectural malformation of the smooth muscle due to localized myopathy is the key. Focal stasis in SDI affecting permeability and increased exposure to macromolecules, and antigens may give rise to immune-mediated arthritis. Surgical management can reduce and cure the symptoms of such patients.
\end{abstract}

Keywords: JIA, Chronic abdominal distention, Segmental dilatation of intestine, Juvenile idiopathic arthritis, Localized myopathy, Enteropathy

\footnotetext{
* Correspondence: dr.santosh25@gmail.com

'Department of Pediatric Surgery, All India Institute of Medical Sciences (AllMS) Bhubaneswar, Sijua, Patrapada, Bhubaneswar, Odisha PIN-751019,

India

Full list of author information is available at the end of the article
}

() The Author(s). 2021 Open Access This article is licensed under a Creative Commons Attribution 4.0 International License, which permits use, sharing, adaptation, distribution and reproduction in any medium or format, as long as you give appropriate credit to the original author(s) and the source, provide a link to the Creative Commons licence, and indicate if changes were made. The images or other third party material in this article are included in the article's Creative Commons licence, unless indicated otherwise in a credit line to the material. If material is not included in the article's Creative Commons licence and your intended use is not permitted by statutory regulation or exceeds the permitted use, you will need to obtain permission directly from the copyright holder. To view a copy of this licence, visit http://creativecommons.org/licenses/by/4.0/. 


\section{Background}

Segmental dilatation of the intestine (SDI) is an unusual condition with varied clinical presentations. More than $50 \%$ of cases detected in the neonatal period with features of intestinal obstruction and or perforation [1]. Older children present with anaemia, hypoproteinaemia, malabsorption, failure to thrive, and abdominal pain [1]. Although the diagnostic criteria of SDI are well established, the etiology is still unclear. We are reporting a case of SDI in a 5-yearold child, who presented with chronic abdominal distension \& was also diagnosed to have juvenile idiopathic arthritis (JIA). Her joint symptom disappeared completely after the resection of SDI. We reviewed the described hypothesis, analyzed the histological findings, and suggested the role of localized myopathy as a possible etiology. We have further emphasized the link between the SDI with development of arthritis.

Case presentation A 5-year-old female child was referred from the Department of Paediatrics for evaluation of chronic abdominal distension since last 3 years. The child was getting treated for juvenile idiopathic arthritis (JIA) involving the bilateral ankles, knees, and wrists. There was no history of constipation and vomiting or delayed passage of meconium. There was no similar illness history in the family. On general examination the child had a weight of $10.2 \mathrm{~kg}$ and a height of $85 \mathrm{~cm}$, which was less than 3rd centile of normal growth as per age indicating failure to thrive. On clinical examination, there were swelling and tenderness with warmth on the bilateral knee, ankle, wrist, elbow, and proximal interphalangeal joints. The abdomen was grossly distended without any palpable mass and the rectum was empty.

X-ray abdomen revealed grossly distended centrally placed bowel loops with an air-fluid level crossing midline. A contrast-enhanced computerized tomography (CECT) of abdomen revealed evidence of malrotation of small bowel with few grossly dilated ileal loops. Large bowel was normal. But as the child was asymptomatic and had no history of vomiting; small bowel obstruction was unlikely as per the clinical judgment. Laparotomy was planned to find out possible etiology and correction of malrotation. On laparotomy, a hugely dilated segment of ileum $(22.5 \mathrm{~cm} \times 20 \mathrm{~cm})$ was noted approximately $40 \mathrm{~cm}$ from the ileocecal junction along with features of malrotation (Fig. 1). There was an abrupt transition between the dilated \& normal ileum with no distal intrinsic or extrinsic obstruction. There was no evidence of volvulus and the dilated segment was featureless \& healthy looking with normal mesentery. Resection of the dilated portion with end to end anastomosis was done and Ladd's procedure was performed.

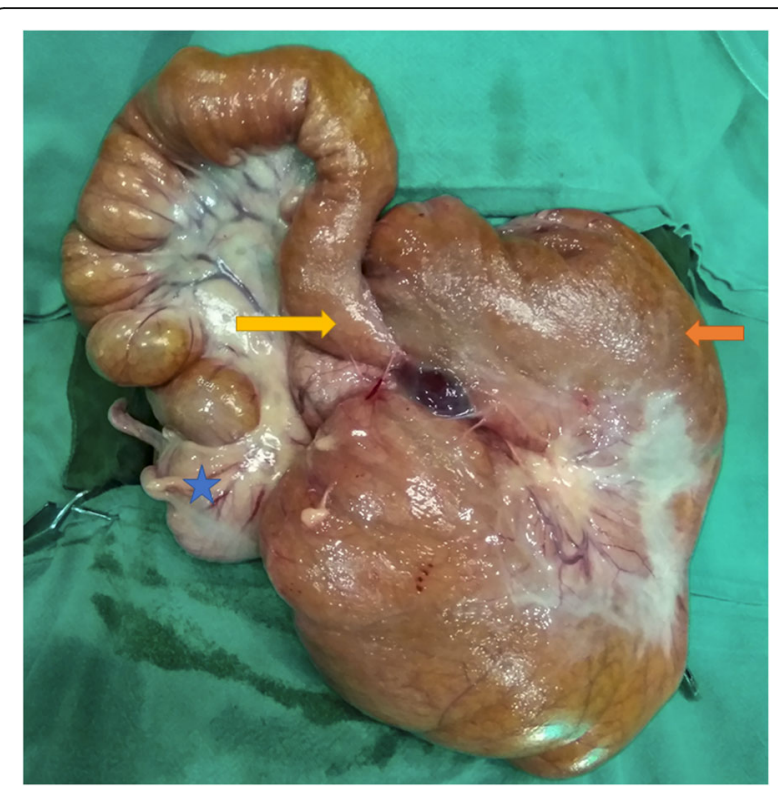

Fig. 1 Operative findings showing hugely dilated segment of ileum (orange arrow), abrupt dilatation (yellow arrow suggesting normal distal bowel), and caecum (indicated by blue star)

On cutting open the dilated segment, the mucosal folding was stretched out but having normal rugosity. Histologic examination of the resected specimen revealed presence of heterotrophic gastric mucosa of both fundic \& pyloric type with focal epithelial hyperplasia (Fig. 2a). The underlying sub-mucosa was deficient at sites with the absence of muscularis mucosa. Muscularis mucosae and propria were disorganized showing patchy atrophy with fibrosis and focal duplication of inner circular layer (Fig. 2b). There were degenerative changes in the form of cytoplasmic vacuoles and granules of smooth muscle cells (Fig. 2c). Ganglion cells and nerve bundles were present. CD-117 immune stain highlighted the presence of interstitial cell of Cajal (Fig. 2d). Cut margins of both intestinal ends were unremarkable.

Apart from these structural and degenerative changes, chronic inflammatory changes of antigenic stimuli such as increased in intraepithelial lymphocytes (IELs), aphthous ulceration, lymphoid aggregates, prominence of Peyer patches, and an occasional non-caseating granuloma within a germinal center were also noted (Fig. 3A-D). The presence of bacterial colonies were seen in the surface as well as in the luminal mucus layer. The inflammation was of variable degree with focal transmural extension composed of lymphocytes, plasma cells, neutrophils, and few eosinophils.

The child was discharged on post-operative day 7 and is doing well on follow-up. At 6 weeks of follow-up, the child's symptoms related to arthritis were controlled and steroids were gradually weaned off by 6months. 


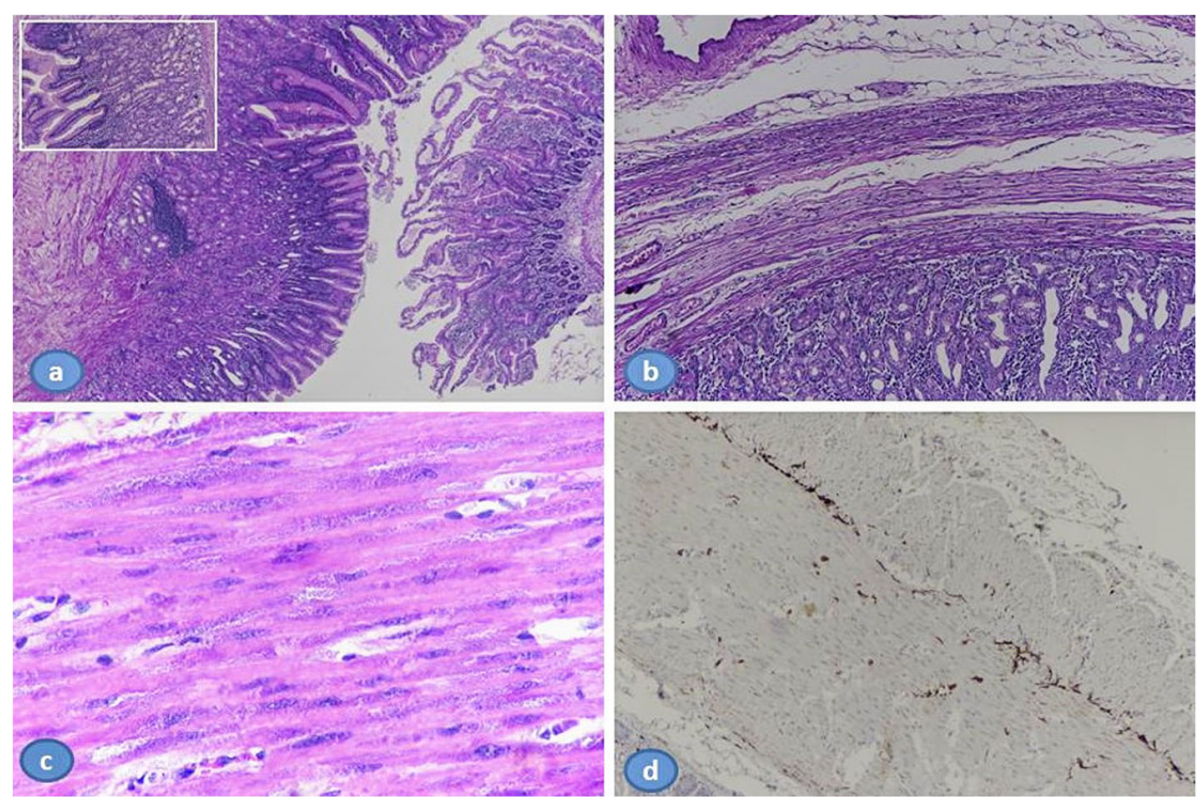

Fig. 2 Structural changes. A Showing heterotopic gastric mucosa containing fundic type of gland (inset—showing pyloric gland). B Disorganization \& atrophy of muscularis propria with focal duplication of inner circular layer. C Cytoplasmic granular degeneration of smooth muscle fibers. D Normal preservation of interstitial cell of cajal highlighted by CD117

Currently, the child is not under any medications and is completely asymptomatic for last 2.5 years.

\section{Discussion}

Segmental dilatation of intestine (SDI) though uncommon is a well-known entity. More than 150 cases of SDI are reported in the literature [1-11]. The presentation and associations are well described; however, the etiology of this disease is largely unknown and association with JIA has never been reported. Various theories have been proposed regarding the pathogenesis of SDI such as extrinsic compression of segment of the intestine by umbilical ring, disturbance during splitting of notochord from ectoderm, presence of heterotrophic gastric

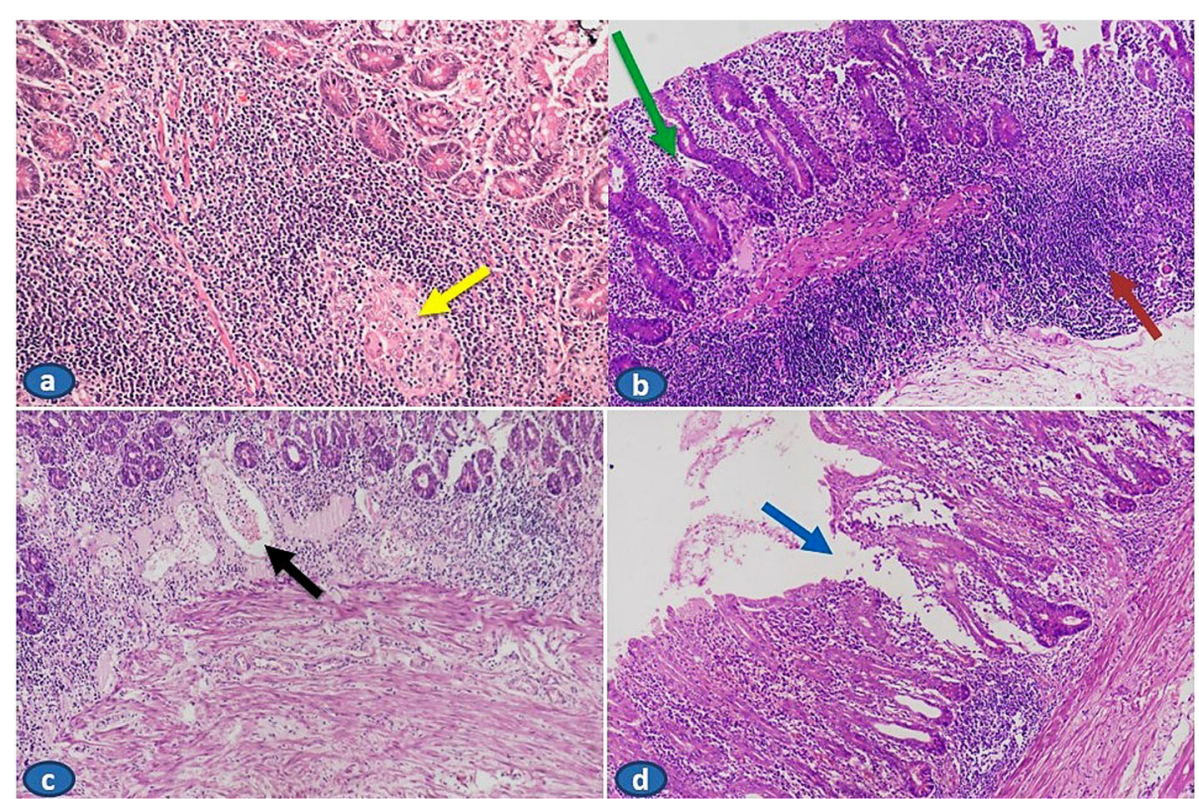

Fig. 3 Immunological changes. A Lymphoid hyperplasia with granulomatous reaction (yellow arrow). B Architectural change (green arrow) with prominence of lymphoid aggregates (orange arrow). C Dilated lacteals (black arrow). D Apthus ulcer (blue arrow) 
mucosa (HGM) and ectopic pancreatic tissue, and localized vacuolization representing muscle atrophy indicating localized myopathy of smooth muscle cells but none is conclusive [2-6].

Recent reports suggest, interstitial cells of cajal (ICC) do play a major role in causation of SDI [7, 8]. Okada et al. found ICCs around Auerbach's plexus of the dilated intestine to be highly deficient $[7,8]$. However, Soyer et al. (2015) found no mucosal abnormality, ganglia, plexuses, and ICC were normal in distribution in the dilated segment. They could detect a supernumerary intestinal muscle coat with additional neural plexus between the longitudinal and circular muscle of the small intestine, and they attributed this haphazard orientation of muscle fibers causing intestinal pseudo-obstruction as a cause of SDI [1].

In our case, child presented late at the age of 5 years with complains of persistent abdominal distension which is unusual. She had radiological features of malrotation, but there was no other gastrointestinal complaint. The size of the SDI $(22.5 \times$ $20 \mathrm{~cm}$ ) is one of the largest among other SDI described in literature. Histopathologic study showed the presence of HGM both fundic and pyloric type with focal hyperplasia. There was haphazard arrangement of muscle layer, and at some places, the muscularis propria was thickened with focal duplication of inner circular layer. The cytoplasm of the muscle showed marked granular degenerative changes along with cytoplasmic vacuoles of the muscle fiber indicating myopathy. Nerve bundles and ganglion cells were also arranged haphazardly. ICCs were present as highlighted by CD 117 on immunohistochemistry. Hence, we believe, there is no single etiology of SDI, and due to its varied clinical and histological presentation, it must be multifactorial in origin. Architectural malformation of the smooth muscle due to localized myopathy may be the most important event for development of SDI. The haphazard arrangement of the nerve bundles and ganglion cells indicates that enteric neuropathy most probably augments the action of localized myopathy for development of segmental dilatation of the intestine.

Association of JIA in this child can be related to the presence of the SDI. Several autoimmune diseases are known to be associated with alteration of intestinal microbial flora [9]. The relationship between inflammatory joint disease and the gastrointestinal tract is well established. Migration and homing of immune cells from the gut to synovium causing arthritis may represent a modifiable link between intestinal immunity and chronic arthropathies [10]. Joint involvement also occurs with other gastrointestinal diseases such as Whipple disease, celiac disease, and following intestinal bypass surgery for obesity in adults [10].

Persistent gastrointestinal infection or loss of tolerance against resident microbiota is generally accepted to be involved in the development of inflammatory bowel disease (IBD) \& associated musculoskeletal symptoms [11]. Reactive arthritis develops within 2-3 weeks after the onset of diarrhoea following infection with salmonella, shigella, yersinia, \& campylobacter species with an incidence ranging from 2 to 33\%. The risk of developing arthritis is more following Yersinia infection in cases with HLAB 27 genotype [12-14]. Bazso et al. described association of JIA and functional constipation secondary to Hirschsprung disease which resulted in remission of arthritis after surgical resection [15].

In our case, the micromorphological findings such as prominent lymphoid aggregates, noncaseating granuloma, and architectural changes indicate chronic lowgrade inflammatory injury of immunological origin. We hypothesize that SDI-related focal stasis might have affected the permeability of the affected segment, thus increasing exposure to macro-molecule, microbial, and dietary antigens, giving rise to arthritis. This was further established by the fact that after surgery, the arthritis resolved and the medications (steroids) were weaned off gradually and the child is asymptomatic without any medication till last follow-up.

\section{Conclusion}

Etiology of SDI is multifactorial with architectural malformation of the smooth muscle due to the localized myopathy is the key. The focal stasis in SDI affecting permeability and increased exposure to macromolecules and antigens may give rise to immune-mediated arthritis. Additional research is required to improve our understanding of the mechanism by which an altered microbiota might predispose to arthritis and development of IBD in children. Surgical management can reduce and cure the symptoms of such patients.

\section{Abbreviations \\ SDI: Segmental dilatation of intestine; JIA: Juvenile idiopathic arthritis; CECT: Contrast-enhanced computerized tomography; HGM: Heterotrophic gastric mucosa; ICC: Interstitial cells of cajal; IBD: Inflammatory bowel disease}

\section{Acknowledgements}

Not applicable

Authors' contributions

Study conception \& design: SKM and SP. Data acquisition: SKM, BBT, and ABP, Analysis \& data interpretation: SKM, SP, and SCS. Drafting of the manuscript: SKM, Critical revision: MKM, BBT, and ABP. The authors have read and approved the manuscript.

Funding

The authors received no specific grant from any funding agency in the public, commercial, or not-for-profit sectors. 
Availability of data and materials

Available upon request.

\section{Declarations}

Ethics approval and consent to participate

Not applicable

\section{Consent for publication}

Written informed consent was obtained from the father of the patient.

\section{Competing interests}

The authors declares that there is no conflict of interest with respect to the authorship and/or publication of this article.

\section{Author details}

'Department of Pediatric Surgery, All India Institute of Medical Sciences (AllMS) Bhubaneswar, Sijua, Patrapada, Bhubaneswar, Odisha PIN-751019, India. ${ }^{2}$ Department of Pathology, All India Institute of Medical Sciences (AllM S) Bhubaneswar, Sijua, Patrapada, Bhubaneswar, Odisha PIN-751019, India. ${ }^{3}$ Department of Medical Gastroenterology, All India Institute of Medical Sciences (AllMS) Bhubaneswar, Sijua, Patrapada, Bhubaneswar, Odisha PIN-751019, India.

Received: 11 September 2020 Accepted: 19 May 2021

Published online: 09 August 2021

\section{References}

1. Soyer T, Talim B, Tanyel F. Segmental dilatation with supernumerary intestinal muscle coat in a neonate. Surgical Case Reports. 2015;1(1):16. https://doi.org/10.1186/s40792-015-0022-8

2. Irving IM, Lister J. Segmental dilatation of the ileum. J Pediatr Surg. 1977; 12(1):103-12. https://doi.org/10.1016/0022-3468(77)90303-7.

3. Heller K, Waag KL, Beyersdorf F. Intestinal duplications-intestinal diverticula-segmental dilatation of the intestine: a common genetic complex. Pediatr Surg Int. 1989:4:249-53.

4. Kobayashi T, Uchida N, Shiojima M, Sasamoto H, Shimura T, Takahasi A, et al. Segmental dilatation of the ileum covered almost entirely by gastric mucosa: report of a case. Surg Today. 2007;37(12):1102-4. https://doi.org/1 0.1007/s00595-007-3526-4.

5. Brown BR, Hennessey I, Lansdale N, Humphrey G. Pancreatic tissue in congenital segmental dilatation of intestine: case presentation and recommendation for treatment. J Pediatr Surg. 2008;43(11):E9-11. https:// doi.org/10.1016/j.jpedsurg.2008.06.043.

6. Cheng W, Lui VCH, Tam PKH. Enteric nervous system, interstitial cells of cajal, and smooth muscle vacuolization in segmental dilatation of jejunum. J Pediatr Surg. 2001;36(6):930-5. https://doi.org/10.1053/jpsu.2001.23979.

7. Okada T, Sasaki F, Honda S, Cho K, Matsuno Y, Itoh T, et al. Disorder of interstitial cells of cajal in a neonate with segmental dilatation of the intestine. J Pediatr Surg. 2010;45(6):E11-4. https://doi.org/10.1016/j. jpedsurg.2010.03.024.

8. Sakaguchi T, Hamada $Y$, Nakamura $Y$, Hamada H, Kwon AH. Absence of the interstitial cells of cajal in a neonate with segmental dilatation of ileum. J Ped Surg Case Reports. 2016;5:19-22. https://doi.org/10.1016/j.epsc.2015.12. 009.

9. Tejesvi MV, Arvonen M, Kangas SM, Keskitalo PL, Pirttila AM, Karttunen TJ, et al. Faecal microbiome in new-onset juvenile idiopathic arthritis. Eur J Clin Microbiol Infect Dis. 2016;35(3):363-70. https://doi.org/10.1007/s10096-015-2 $548-\mathrm{X}$.

10. Goel R, Danda D, Avinash B, Pulimood AB, Mathew J, Ramakrishna BS. Clinico-pathological correlation of nonspecific inflammation in bowel histology with joint manifestation in a tertiary center in South India. Rheumatol Int. 2013;33(8):2149-52. https://doi.org/10.1007/s00296011-2332-x.

11. Orlando A, Renna S, Perricone G, Cottone M. Gastrointestinal lesions associated with spondyloarthropathies. World J Gastroenterol. 2009;15(20): 2443-8. https://doi.org/10.3748/wjg.15.2443.

12. De Keyser F, Baeten D, Van den Bosch F, De Vos M, Cuvelier C, Mielants H, et al. Gut inflammation and spondyloarthropathies. Curr Rheumatol Rep. 2002;4(6):525-32.
13. Inman RD. Arthritis and enteritis - an interface of protean manifestations. Rheumatol. 1987:14(3):406-10.

14. Camp JG, Kanther M, Semova I, Rawis JF. Patterns and scales in gastrointestinal microbial ecology. Gastroenterology. 2009;136(6):1989-2002. https://doi.org/10.1053/j.gastro.2009.02.075.

15. Bazso A, Sevcic K, Orban I, Suto G, Poor G, Kiss E, et al. Association of juvenile idiopathic arthritis and functional constipation. Int J Clin Rheumatol 2009;4(6):673-80. https://doi.org/10.2217/ijr.09.60.

\section{Publisher's Note}

Springer Nature remains neutral with regard to jurisdictional claims in published maps and institutional affiliations.

\section{Submit your manuscript to a SpringerOpen ${ }^{\circ}$ journal and benefit from:}

- Convenient online submission

- Rigorous peer review

- Open access: articles freely available online

- High visibility within the field

- Retaining the copyright to your article

Submit your next manuscript at $\boldsymbol{\nabla}$ springeropen.com 